of imbalance sap the patient's confidence, and persistent tinnitus increases his fears that he has a serious cerebral malady. Psychological symptoms may eventually dominate the clinical picture.

Wide variation in the disease means that each patient must be treated individually ; moreover, it makes assessment of the effects of therapy almost impossible. All patients, and particularly those with vertigo and tinnitus, must be assured -and often reassured-that they are not suffering from a cerebral or fatal malady. Deaf patients may need a hearingaid. Those suffering only occasional mild attacks of imbalance need no treatment, while others with frequently recurring bouts may be helped by various drugs, notably dimenhydrinate (Dramamine), promethazine theodate (Avomine), prochlorperazine (Stemetil), thiethylperaxine (Torecan), eriodictyol glycoside (Lipoflavonoid), phenobarbitone, or a salt-free diet. ${ }^{2}$ If nausea and vomiting are troublesome dimenhydrinate and promethazine are most helpful, and during a severe acute bout of vertigo can be given intramuscularly. Stellate-ganglion block also occasionally produces a dramatic cessation of vertigo and rapid recovery of hearing. Medical treatment should be tried for all patients, and it may be all that can be offered to those with bilateral disease. However, when vertigo produces prolonged incapacity surgical operation must be considered.

Vertigo can usually be stopped by surgical destruction of the affected labyrinth or division of the appropriate vestibular nerve. As labyrinthectomy always causes total deafness in that ear the operation is reserved for those patients with unilateral disease and severe loss of hearing in the affected ear. Section of the vestibular nerve ${ }^{3}$ has the great advantage of preserving the hearing. The difficulties of this operation have led otolaryngologists to use ultrasonic waves, directing them to the lateral semicircular canal to destroy the labyrinth and yet preserve hearing. ${ }^{4}$ The results, however, are not likely to be any better than those from surgical neurectomy. Bilateral labyrinthectomy or vestibular neurectomy is never justified, for apart from any loss of hearing a patient remains permanently unstable in the dark or with his eyes closed. When the disease is bilateral other treatment must be given. Drainage of the endolymphatic sac into the subarachnoid space has been revived, but the results are not encouraging. As vascular spasm within the internal auditory system can be relieved by a combined stellate and upper dorsal ganglionectomy ${ }^{5}{ }^{6}$ the operation has been used for both unilateral and bilateral disease with varying degrees of success. Ganglionectomy has the advantage of not destroying labyrinthine or cochlear function.

\section{Lightning Seizures}

Lightning major convulsions are perhaps the most frequently misdiagnosed epileptic seizures that occur in childhood. They are certainly commoner in infants than petit mal attacks, with which they are often confused. ${ }^{12}$ Other names for the condition include massive spasms, ${ }^{3}$ flexion spasms, ${ }^{4}$ infantile spasms, ${ }^{1}$ myoclonic seizures of infancy, jack-knife spasms, salaam attacks, and in German Nickkrampfe or Salaamkrampfe.

A lightning major convulsion consists of a sudden momentary impairment or loss of consciousness which is associated with an abrupt alteration of posture. The change of posture differs from one patient to another but is constant in any one patient. The commonest form is for the head and trunk to be flexed suddenly as the arms are semiflexed at the elbows, pronated in the forearms, and abruptly raised and flexed at the shoulders. At the same time the lower limbs stiffen and extend. The appearance is one of "headnodding " or " jack-knifing." Other patterns with arching of the back have been described, and partial attacks in which not all limbs are involved occur. Any posture is maintained for only a fraction of a second, and there appear to be momentary muscular relaxation and loss of tone.

Characteristically attacks come at intervals of between one and five seconds in bouts of up to a dozen or more. They may be preceded by agitated behaviour; the baby may cry as if suffering from colic or writhe about as if in pain. Some infants appear to find the attacks themselves painful or frightening and may cry after each bout. Others appear to be quite unconcerned before, during, or after their attacks. Lightning convulsions are most likely to come during inattention, and especially when infants are drowsy, though they may occur throughout the day.

The electroencephalograms of almost all infants with this type of convulsion are grossly abnormal. The commonest abnormalities were described by F. A. Gibbs and E. L. Gibbs ${ }^{5}$ as " hypsarrhythmia" in which "large amplitude generalized irregular slow waves are seen mixed with sharp waves and spikes, varying from moment to moment in duration and location." Other less characteristic patterns also occur, however, and Ruth Harris ${ }^{6}$ in her recent paper points out that it is not uncommon to find "slow waves and discharges appearing in intermittent bursts alternating every few seconds with periods of apparent equipotentiality."

Associated with a variety of disorders due to gross structural abnormalities or diffuse disease of the brain, lightning convulsions may be found in patients with cerebral malformations or birth injury, and in children who have suffered from encephalopathies-for example, encephalitis after vaccination. They may also affect children with inborn errors of metabolism such as phenylketonuria, degenerative diseases with demyelination, or the cerebral lipoidoses. ${ }^{78}$ As pointed out by $R$. S. Illingworth, ${ }^{9}$ lightning convulsions may be the first indication of a rapidly progressing dementia in infants who have developed normally and seemed healthy previously.

Though this affliction begins most commonly in the first year of life it may do so at any time in later childhood. It has been suspected for some time that many "drop attacks"

\footnotetext{
1 Bower, B. D., and Jeavons, P. M., Lancet, 1959, 1, 605.

Pampiglione, G., Arch. Dis. Childh., 1964, 39, 571.

3 Buchanan, D., Med. Clin. N. Amer., 1946, 30, 163.

Gastaut, H., and Roger, A., Pédiatrie, 1953, 8, 603.

- Gibbs, F. A., and Gibbs, E. L., An Atlas of Electro-encephalography, 2nd ed., 1952, Addison Wesley Press, Cambridge, Mass.

- Harris, R., Arch. Dis. Childh., 1964, 39, 564.

'Millichap, J. G., Buckford, R. G., Klass, P. W., and Backus, R. E., Epilepsia (Amst.), 1962, 3, 188.

Tucker, J. S., and Solitare, G. B., ibid., 1963, 4, 45.

- Illingworth, R. S., Arch. Dis. Childh., 1955, 30, 529.

10 Gastaut, H., The Epilepsies, 1953, Springfield, Ohio.

11 Bray, C. A. R., and Bower, B. D., Devel. Med. and Child Neurol., 1963, $5,409$.

12 Ingram, T. T. S., and Ratcliffe, S. G., ibid., 1963, 5, 313.

${ }^{13}$ Sorel, L., and Dusaucy-Bauloye, A., Acta Neurol. belg., 1958, 58, 130.

14 Gastaut, H., Salkiel, J., Raybaud, G., Pitot, M., and Meynadier, A., Pédiatrie, 1959, 14, 35.

15 Bower, B. D., and Jeavons, P. M., Arch. Dis. Childh., 1961, 36, 23.

16 Bray, P. F., Pediatrics, 1963, 32, 169.

17 Stamps, F., Gibbs, E. L., Rosenthal, I. M., and Gibbs, F. A., F. Amer. med. Ass., 1959, 171, 408.
} 
or "akinetic seizures" found in older children and adults resemble myoclonic seizures and that they are due to an initial brief generalized muscular jerk rather than to hypotonia. $^{10}$ G. Pampiglione's recent finding that electrical activity in the muscles is absent for a short time immediately after the generalized jerk of a lightning major convulsion supports this viewpoint. ${ }^{2}$

The commonly used anticonvulsant drugs are seldom effectual remedies for these patients, though some success has been claimed for sulthiame. ${ }^{112}$ Corticotrophin or prednisolone often supresses the convulsions and improves the electroencephalogram, ${ }^{13}$ but most patients relapse soon after treatment is discontinued. ${ }^{14}$ The seizures recur and the electroencephalogram becomes abnormal again. ${ }^{15-17}$

Inevitably patients whose lightning major convulsions are symptoms of gross malformation or damage of the brain have a poor long-term prognosis and many are mentally defective, paralysed, and epileptic in later life. It was hoped that the short-term improvement with corticotrophin or prednisolone in previously healthy children might be sustained. But recent studies suggest that it is not, ${ }^{15}$ and the findings of $\mathrm{Harris}^{6}$ are depressing. Of 75 children with lightning major convulsions (caused by various neurological disorders) who were treated with corticotrophin only six were considered to be healthy and of average intelligence on follow-up between one and two years later. The effect of long-term treatment in children in whom these seizures start in infancy after apparently normal previous development is still under assessment. Major advances in treatment are unlikely until the underlying disease process is understood. ${ }^{8}$

\section{Stress and Gastro-intestinal Haemorrhage}

The association of acute peptic ulceration with various types of stress has been recognized for more than a hundred years. T. B. Curling ${ }^{1}$ in 1842 collected eleven cases that had followed burns, and Harvey Cushing ${ }^{2}$ described acute gastric erosions after intracranial injury which he attributed to hypothalamic irritation and overstimulation of the sympathetic nervous system. Since then the condition has been noted to accompany accidents and operations of many kinds, ${ }^{3-6}$ as well as severe infections and cardio-respiratory failure ${ }^{7}$ and lesions of the frontal lobes. ${ }^{8}$

Prominent features are the delay in onset of symptoms, which occur as the patient is recovering from the original stress, the dramatic suddenness of abdominal discomfort and bleeding, and the distressingly high mortality. They are exemplified by a recent analysis ${ }^{9}$ of 26 cases in a French unit devoted to the treatment of severe respiratory insufficiency. The patient was usually an elderly male with cardio-respiratory failure due to chronic obstructive disease of the airways, with consequent hypoxia and hypercapnia. Two or three days after the start of treatment, which varied from simple supportive measures to full-scale resuscitation with tracheostomy and assisted respiration, the patient had a small blood-stained vomit without warning. A few hours later massive gastro-intestinal bleeding supervened, often accompanied by alarming abdominal distension, and death commonly followed within twenty-four hours despite blood transfusions, administration of pressor agents, and duodenal aspiration. The fatality rate was $77 \%$.

The incidence of the syndrome in the French series was $6.5 \%$ and three-quarters of the patients had long-standing lung disease. (Peptic ulceration is found in about 20\% of patients with chronic pulmonary disorders, ${ }^{10}$ compared with $1.6 \%$ of a general hospital population. ${ }^{7}$ ) The other patients had various types of coma, cardiac insufficiency, and septicaemia. The lesions in those patients who were examined at necropsy were notably uniform in appearance. Intense vascular congestion and submucous haemorrhages were present in the stomach and duodenum and to a less extent in the jejunum and colon, and they were accompanied by multiple superficial erosions. Normally the damage did not extend beyond the submucosa, but occasionally perforation had occurred, an observation which other workers have recorded. Perivascular oedema and haemorrhages were also found in the central grey matter of the spinal cord, in the medulla, and in the diencephalon.

It seems likely that peptic ulceration due to stress has a single aetiological mechanism, conditioned no doubt by such predisposing factors as hypoxia, hypercapnia, mucosal ischaemia, or a dyspeptic diathesis. Cushing postulated a hypothalamic neurogenic stimulus, but nowadays it is fashionable to invoke hypothalamic-hypophysial pathways, secretion of corticotrophin, and adrenal stimulation. The action of corticosteroids on gastric secretion is debated, but a combination of excessive secretion of acid and pepsin together with depression of the normal mechanisms of healing-both effects have been attributed to corticosteroids-could cause gastric erosions. An alternative explanation is suggested by the work of Räsänen, ${ }^{11}$ who observed degranulation of mast cells in the gastro-intestinal tract (indicating liberation of histamine and heparin) in mice subjected to stress or when given corticosteroids.

There remains the problem of anticipating the syndrome in man, so that prompt action can be taken to avoid a fatal outcome. The elderly, especially those with a history of chest disease or dyspepsia, are particularly at risk, and the prophylactic administration of antacids has been recommended. Prompt transfusion at the first sign of bleeding is essential, and this will depend on recognizing the significance of the early symptoms. The French workers ${ }^{9}$ suggest that spinal anaesthesia or moderate hypothermia might be justified for what is often a desperate situation.

The next session of the General Medical Council will open on Tuesday, $25 \mathrm{May}$, at 2.15 p.m., when the President, the Rt. Hon. Lord Cohen of Birkenhead, will take the chair and will deliver an address.

${ }^{1}$ Curling, T. B., Med.-chir. Trans., 1842, 25, 260

2 Cushing, H., Surg. Gynec. Obstet., 1932, 55, 1.

8 Roberts, P. A. L., Brit. med. Э., 1954, 1, 1295.

'Blundell, A., ibid., 1954, 2, 133.

${ }^{5}$ Breckenridge, I. M., Walton, E. W., and Walker, W. F., ibid., 1959, 2 1362.

- Choudhury, M., ibid., 1963, 1, 448.

' Flint, F. J., and Warrack, A. J. N., Lancet, 1958, 2, 178.

${ }^{8}$ Arteta, J. L., Brit. med. F., 1951, 2, 580.

- Bourgeois, P., Rogé, J., Garaix, J. P., Martin, E., and de Roissand, F., Sem. Hop. Paris, 1964, 40, 2931.

${ }^{10}$ Cohen, A. C., and Jenney, F. S., Amer. Rev. resp. Dis., 1962, 85, 130

${ }^{11}$ Räsänen, T., Gastroenterology, 1963, 44, 168. 